\title{
Hybrid
}

Revue des arts et médiations humaines

$7 \mid 2021$

Le réseau créatif des langu.ages

\section{Translating a work of digital literature into several languages: a case study}

\section{Serge Bouchardon and Nohelia Meza}

\section{(2) OpenEdition}

1 Journals

\section{Electronic version}

URL: https://journals.openedition.org/hybrid/672

DOI: $10.4000 /$ hybrid. 672

ISSN: 2276-3538

\section{Translation(s):}

Traduire une œuvre de littérature numérique en plusieurs langues : une étude de cas - URL : https:// journals.openedition.org/hybrid/666 [fr]

Publisher

Presses universitaires de Vincennes

Electronic reference

Serge Bouchardon and Nohelia Meza, "Translating a work of digital literature into several languages: a case study", Hybrid [Online], 7 | 2021, Online since 08 April 2021, connection on 12 April 2022. URL: http://journals.openedition.org/hybrid/672 ; DOl: https://doi.org/10.4000/hybrid.672

This text was automatically generated on 12 April 2022.

Revue Hybrid 


\title{
Translating a work of digital literature into several languages: a case study
}

\author{
Serge Bouchardon and Nohelia Meza
}

\section{Introduction}

1 This paper offers an overview of the different experiences in translating the interactive narrative Déprise. ${ }^{1}$ Our aim was to learn about the various strategies that the process involved. In order to do so, we have asked the English, Italian, Spanish, and Portuguese translators of the work for feedback on the translation process: Valerie Bouchardon (Loss of Grasp, 2010), Giovanna di Rosario (Perdersi, 2011), Martha Asunción Alonso (Perderse, 2013), and Diogo Marques (Perda de controlo, 2016). Based on the written exchanges with the translators, we discuss the following points: 1) the modes of collaboration between author and translator (programming strategy between translator and author; the translator's digital literacy and familiarity with digital literature; the translator's visibility); 2) the importance of translating specific dimensions of digital literature (code migration, semiotic forms and gestures, embedded voices). Additionally, we briefly discuss some future research trajectories on translating digital literature (the role of indirect translation (Gambier, 1994), the cultural dimension of the works, translation as reinvented memory). Lastly, following the four dimensions of translating digital literature identified by Manuel Portela, Søren Pold, and María Mencía's ${ }^{2}$ (2018) - 1) translinguistic; 2) transcoding; 3) transmedial; 4) transcreation - we explore if such dimensions are found in the translator's experiences with Déprise. 


\section{A case study: Déprise (2010)}

\section{General aspects of the digital work}

2 Déprise ${ }^{3}$-(hereafter DP) is an interactive narrative that belongs to a trilogy called Hypertensions, composed of three works: Déprise, Opacité, ${ }^{4}$ and Détrace. ${ }^{5}-D P$ is part of the ELMCIP Anthology of European Electronic Literature (Engberg, Memmott, Prater, 2012) and the English version of the work won the New Media Writing Prize in 2011. DP consists of six scenes that portray the mindscapes of a man who gradually loses grasp of his life. In scene 1 , the protagonist evaluates his life and experiences a stormy moment, a loss of grasp; in scene 2, he meets his future wife on a date; in scene 3 , he reads his wife's twofold love/breakup letter; in scene 4, he reads his son's moving text; in scene 5 , he reaches an auto-confrontation, a complete loss of grasp; and in scene 6 , he decides to confront the situation to take control of his life again. Scene by scene, the reader is challenged to decipher the relationship between the computer's interfacial imaginaries and her/his own self. The work was originally programmed in Flash in 2010 and migrated to JavaScript in 2018. Though this paper is based on the English, Italian, Spanish, and Portuguese Flash versions of the work, it is important to note that the Arabic, Chinese, German, Hungarian, and Polish versions were published in January 2020 and were only developed in JavaScript. ${ }^{6}$

Fig. 1

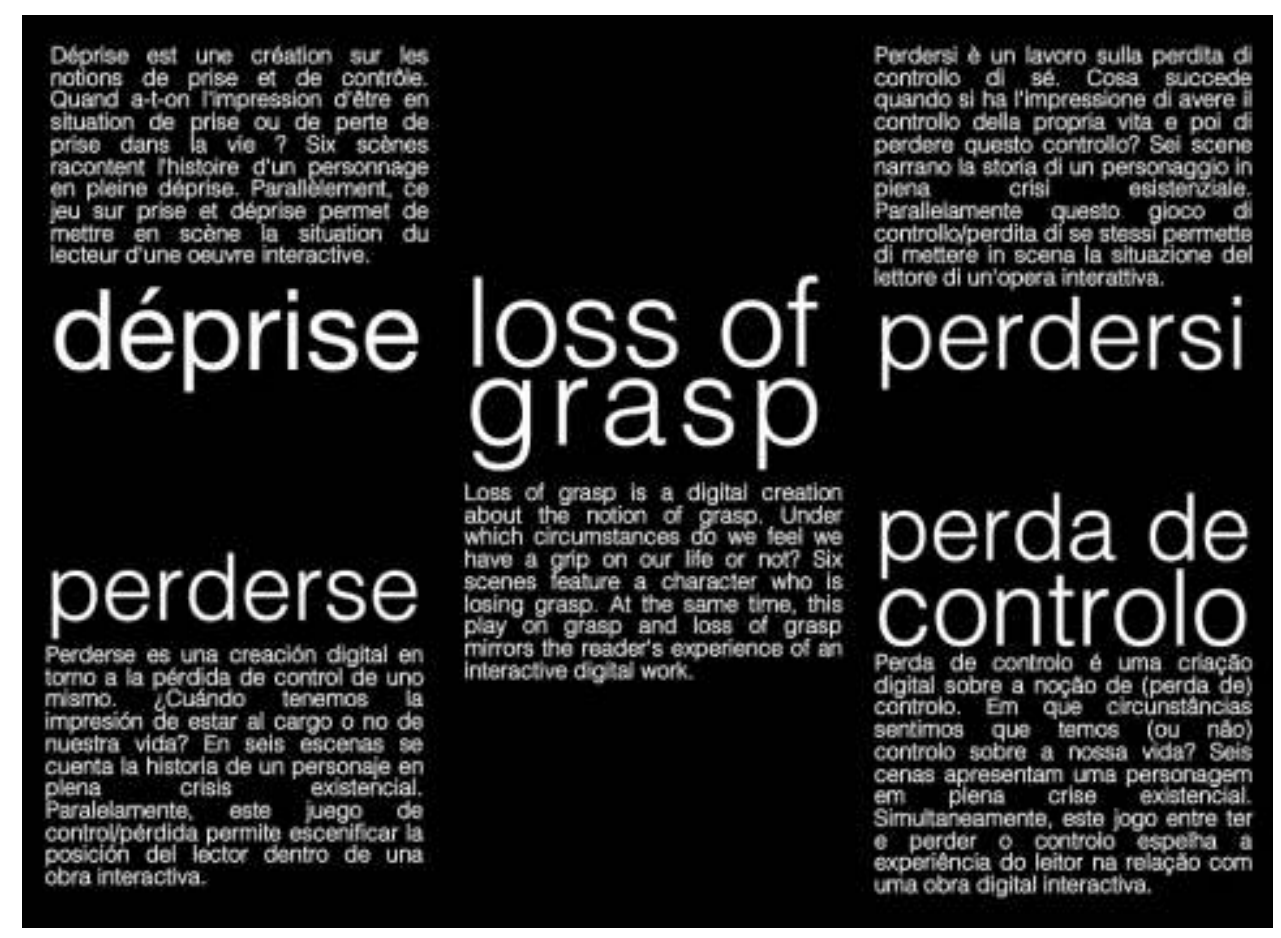

Homepage of Déprise/Loss of Grasp (Flash version).

\section{The interview process}

3 The first interviews and exchanges took place in the same years as the individual translations, with Valerie Bouchardon (Loss of Grasp, 2010), Giovanna di Rosario 
(Perdersi, 2011), Martha Asunción Alonso (Perderse, 2013), and Diogo Marques (Perda de controlo, 2016); afterwards the translators were recontacted in 2018 and 2020. All communication happened by email and the questionnaires were written in French and English. The languages of communication between the author and the translators were the following: V. Bouchardon (French), di Rosario (French/English), Alonso (French), Marques (English). Multilingualism was part of the process from the beginning. For instance, Diogo Marques, who was working with the Portuguese translation of the work, used the English version as the source text and compared certain aspects of his translation with the French original and the Spanish and Italian versions, but communicated with the author in English. Undoubtedly, the exchanges between the author and the translators led to an intercultural and multilingual dialogue.

\section{Different forms of collaboration}

\section{Between text and code}

4 In digital literature, "code" can create a certain distance between the translator and the author. The degree of collaboration between the author and the translator has an effect on the task of programming the "translated text" into different languages. Let us think for example about the importance of semiotic manipulation when recreating similar literary effects in the different versions of a work of digital literature. In the case of $D P$, most of the translators sent the linguistic text to the author without subsequent engagement in the development of the code adaptations to their individual versions.

5 In the interview, V. Bouchardon (Loss of Grasp, 2010) expressed the following: "I preferred to work with the code file. I needed to see the coding context to better understand the process between the code and what appears on screen." This statement raises the question of the structural opacity of any computer program, the question of the mediation of computation between the code and the restitution forms on screen. Di Rosario (Perdersi, 2011) had a similar thought when dealing with the reproduction of the rhetorical figures of the text:

The first concern for me has always been to reproduce "the movements" of the original text in my translation. It's not just a linguistic problem, of course, if I think of Déprise and all its "rhetorical figures," I still wonder if I really managed to render them all in Italian. My aim was not to lose the "invisible" digital text, and I am not thinking, in this case, about the code but about what the code allows the writer and the reader to do.

6 These two examples show the particularity of digital literature when it comes to defining the boundaries between code, author and translator; how does the "code distance" between the author and the translator affect the programming of the digital work into different versions? After the interviews, we noticed that once the linguistic text was sent to the author, programmed into the new version, and released as a trial version between author and translator, the translators would normally ask for changes on their versions after reading and interacting with their version of the work. We noticed that particularly reading time (on the screen), interaction and manipulation issues played an essential role in the translation test version process. 


\section{The translator's digital literacy and familiarity with digital literature}

7 The first critical approach to the translation of DP into a different language (Italian version) was made by di Rosario and Borràs. ${ }^{7}$ The researchers pointed out that the role of the translator in the digital era is changing "as not only does s/he need to translate words, but also images and movements, and sometimes s/he is also required to have the technical competence to do it." By "technical competence," we understand not only the translator's digital literacy (i.e. computer skills) but also certain familiarity with digital literature. In the interviews, di Rosario, Alonso, and Marques answered that $D P$ was the first digital work they had ever translated ${ }^{8}$; and specifically, for Alonso (Perderse, 2013), she had never heard of digital literature before and therefore translating $D P$ was a completely new experience for her.

Regarding this, Marques asks: "Should digital literary works of art only be translated by specialists of digital literature?" A way to answer Marques' interrogation is to think that Alonso (Spanish version) is not a specialist of digital literature and still she was able to translate the work by email communication with the author. However, Alonso's work implied mainly working with the linguistic text and phonetics, and not with the code file as was the case for V. Bouchardon, di Rosario, and Marques himself. Considering that Marques and di Rosario are digital literature researchers, that $\mathrm{V}$. Bouchardon is an ESL teacher and Alonso is a translator, we can also ask ourselves, how does the translator's professional background affect the translation of the source digital text? Is there a specific digital literacy for the translator of digital literature?

Recording voices $(\mathrm{S} 1, \mathrm{~S} 2, \mathrm{~S} 4)$ as part of the translation process is specific to DP. It implies translating the transcript, finding a voice (a person) to perform it, and asking them to read and record the translated transcript and send it to both the translator and author. For example, while working with the Portuguese version, Marques said that "he needed to find three people to recite the text and to have the instrument to record it"; on the same subject, di Rosario mentioned that there is also a very basic technical problem to keep in mind: "[...] in order to translate digital literature, you need several technical tools specially for the recording." In order to record herself, V. Bouchardon used the same sofware (Audacity) as the one she uses with her students and did not need to learn about any specific tool. As we can observe, the degrees of integration when it comes to "technical competence" into the different translation methodologies will vary depending on the professional background of the translator and the collaboration between author and translator. At times, the translators needed to acquire a new set of skills depending on the challenges they confronted; for instance, we can notice that translating and recording new audio content into other languages was underlined by Marques and di Rosario as an important step in their translation methodology, not only for its technical issues but also for its voice-performance challenges, as we shall see in section number 4.3 , "sound and meaning."

\section{The visible and the invisible}

In their article, "Renderings: Translating literary works in the digital age," Marecki and Montfort ${ }^{10}$ discuss how the role of the translator changes when translating digital literature in comparison with traditional works: 
In traditional works, the translator is often invisible, a background figure, sometimes subtly credited or even not mentioned at all. In the case of digital works, the translator becomes visible, an ambassador of the work, often explaining its mechanism and the translation process.

11 The interviews show the translators as active and versatile figures when it comes to working with digital literature. They are able to ask questions, speak to the author about stylistic issues, develop their own methodologies, learn new digital literacy skills (if needed), and experience the act of translation through new ways of aesthetic and literary communication (e.g. by interacting with the digital text, by manipulating it, which is not possible with a printed text). There is a dialogue, an exchange of ideas and at times an involvement in the process of coding. Translators are recognized (see the work's credits) and have a voice and performance in the creative process.

12 Moreover, visibility and invisibility in translating digital literature can be explored in a different way if we go back to the idea of the invisible digital text beyond the screen, and its visible linguistic translation. As di Rosario explains when sharing her translation experiences:

In a certain sense I find that the linguistic translation is "visible," i.e. one can miss the connotation of a word or its nuances, yet easily read the original text, to at least check the original word (the word is there fixed on the page). In digital literature, things get more complicated, because obviously one can translate the linguistic text correctly, and at the same time, part of the meaning of the work - that is also created by other movements, by manipulations, etc. - can get lost.

Di Rosario emphasizes once again the importance of interaction and manipulation of the work to evaluate the aesthetic effects of the linguistic text beyond the screen. It seems that in the translation process, there is certainly a negotiation between the visible and invisible text and its aesthetic outcome. For his part, Marques ${ }^{11}$ underlines the ideas of transparency, translucency, and intersemiotic aspects when translating digital works:

It is interesting to note that the idea of transparency and translucency in digital interfaces that is being propelled by digital technology industries, can be compared to the idea of transparency and translucency in the context of translation. Namely when it comes to translating something that stops being exclusively discursive in order to become multimodal and involve multisensory perception.

Certainly, intersemiotic translation is specific to digital literature where visual, auditory, and tactile channels play an important role in the construction of meaning of the works. Marques' and di Rosario's commentaries show that their concerns as translators are directly related to the competencies that they already have as digital literature readers and researchers (how do we read digital literature?) The fact that di Rosario mentions "digital rhetorical figures" shows a specific aspect of the hidden dynamics of literariness in a work of digital literature, whereas Marques' comments on the complexity of multisensory perception (e.g. App version) show the intersemiotic choices (e.g. shifts of time, context, and texture of semiotic resources), Bouchardon and himself had to make during the process of collaborative translation. 


\section{Translating the specific dimensions of digital literature}

\section{From Flash to JavaScript}

$D P$ is one of the many digital works that has experienced the obsolescence of programming software. Flash, the original software in which the French, English, Italian, Spanish, and Portuguese versions were developed, will stop running in December 2020. In an effort to adapt the work to the current technological challenges, in 2018 the author migrated these four versions into JavaScript. The process of loss and gain in translation was reflected on the "screen disturbances" from one piece of software to another as certain "iconic features" of the Flash version were lost while other "aesthetics aspects" were improved in the Javascript version. It is important to mention that in this paper we do not address the "re-adaptions" of the linguistic text, for example, from the English Flash version to the English JavaScript version; however, we are aware that a "revised translation process" is needed for the already published versions of the work that have been recently re-programmed due to software obsolescence.

Fig. 2

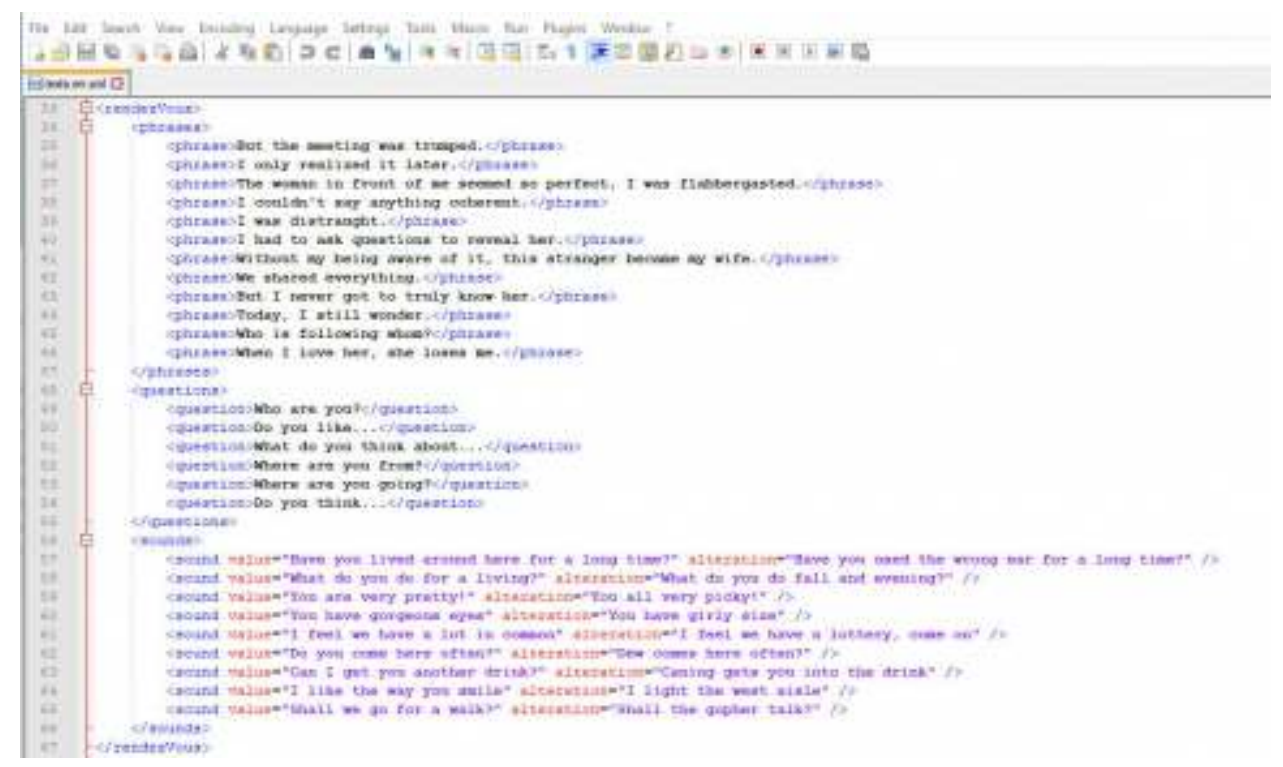

Example of XML code for the scene 2 of Loss of Grasp (for the Flash version in 2010). 
Fig. 3

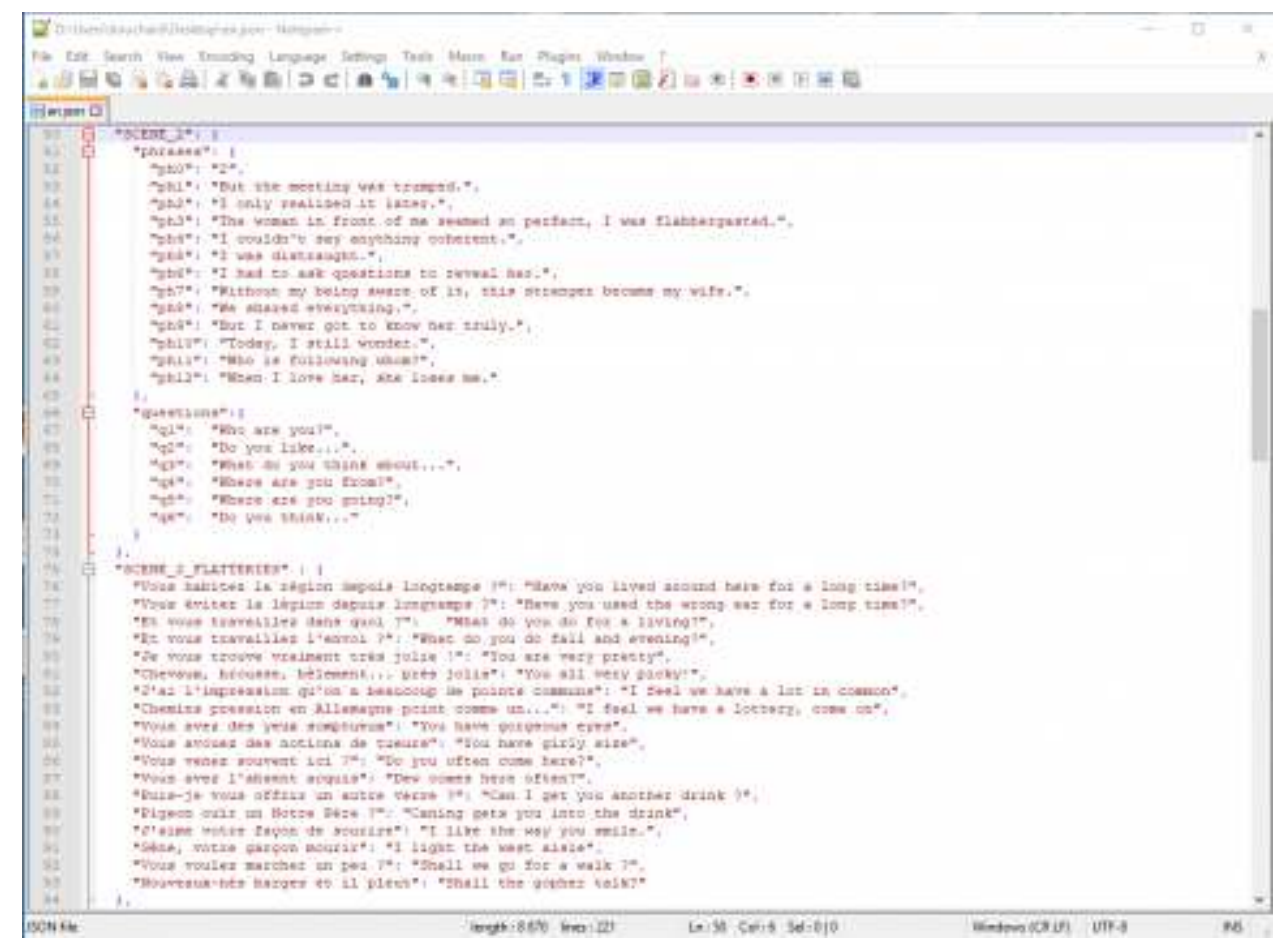

Example of JSON file for the scene 2 of Loss of Grasp (for the smartphone App version in 2018).

With this in mind, we could argue that DP undertook a true process of transcoding (from Flash to JavaScript) and transmediation (from PC to an App for smartphones and tablets). Rethinking the scenes with the tactile dimension (there is no mouse pointer on smartphones) implied a challenging transcreation task for both author and translators. The translation between machine readable codes has had an effect on the visual - and audio - glitch effect in the JavaScript versions. For example, scene 1 (the protagonist's stormy moment, complete loss of grasp) is rendered differently with JavaScript in both the web-based and the App version causing the speed of semiotic displacement to decrease (Figure 4). Other examples include the interaction with the love/breakup letter written by the protagonist's wife in scene 3 where the reading of the text works better with up and down movements (JavaScript) than with right to left (Flash); and the appearance of the individual phrases in scene 6 seems slower, less graspable in JavaScript than Flash. It seems that the "compositional principle"12 of the work could not be expressed in the same way with the shift from Flash to JavaScript. 
Fig. 4

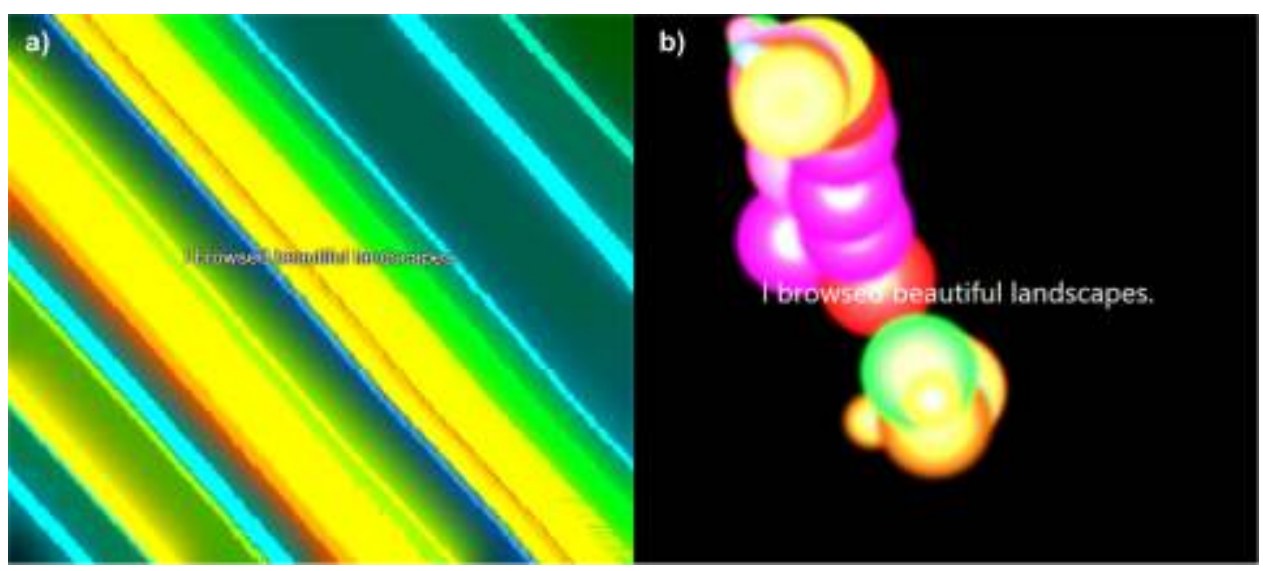

a) Excerpt from scene 1 (Flash version); b) Excerpt from scene 1 (JavaScript web-based version).

\section{Semiotic forms and gestures}

The interplay of semiotic resources (words, images, audio, gestures, etc.) plays an important role in digital literature translation practices. Can we truly achieve intersemiotic cohesion in the translation of certain works of digital literature? For example, when recreating similar literary effects (i.e. figures of speech and rhetorical figures) in the different versions of the piece. In DP such literary and rhetorical effects are possible thanks to "figures of manipulation" (meaning gestural manipulation). These figures rely on a gap between the reader's expectations while manipulating the text and the result on the screen. ${ }^{13}$ Considering this, we argue that the translatability of the literary effect of the figures of manipulation calls for a careful intersemiotic translation in all the current target languages (English, Italian, Spanish, Portuguese).

For example, in scene 2 (the rendez-vous when the protagonist meets his wife), a question mark appears on the screen, waiting for the reader to explore its functionality. A few seconds later, the reader understands that s/he needs to click on the question mark for a series of questions to randomly appear on the screen: "Who are you?", "Do you like...", "What do you think about...", "Where are you from?", “Where are you going?", "Do you think...” (Figure 5a). Following Portela, Pold, and Mencía (2018), this is a key moment for the translation of the piece at different levels: 1) translinguistic: insofar as the translators had to translate the different versions of the linguistic text from the source language to the different target languages (Figure $5 b, 5 c, 5 d$ ); 2) transcoding: insofar as the author had to reproduce this effect on the five new JavaScript versions as well as on the App (migrating platforms); 3) transmediation: insofar as the translators and the author had to integrate certain semiotic modalities into the App version (e.g. multilingual visual narration of the woman); 4) transcreation: insofar as the author and translators had to reproduce the literariness and translatability of the "figures of manipulation" (interaction and manipulation) that unveil the image of the woman's character. The translation process aimed to create a harmony between interaction, manipulation, and the linguistic texts in different languages that construct the same image. The aim is not only to grasp the meaning of the aesthetic elements of expression but also to search for literary patterns. 
Fig. 5
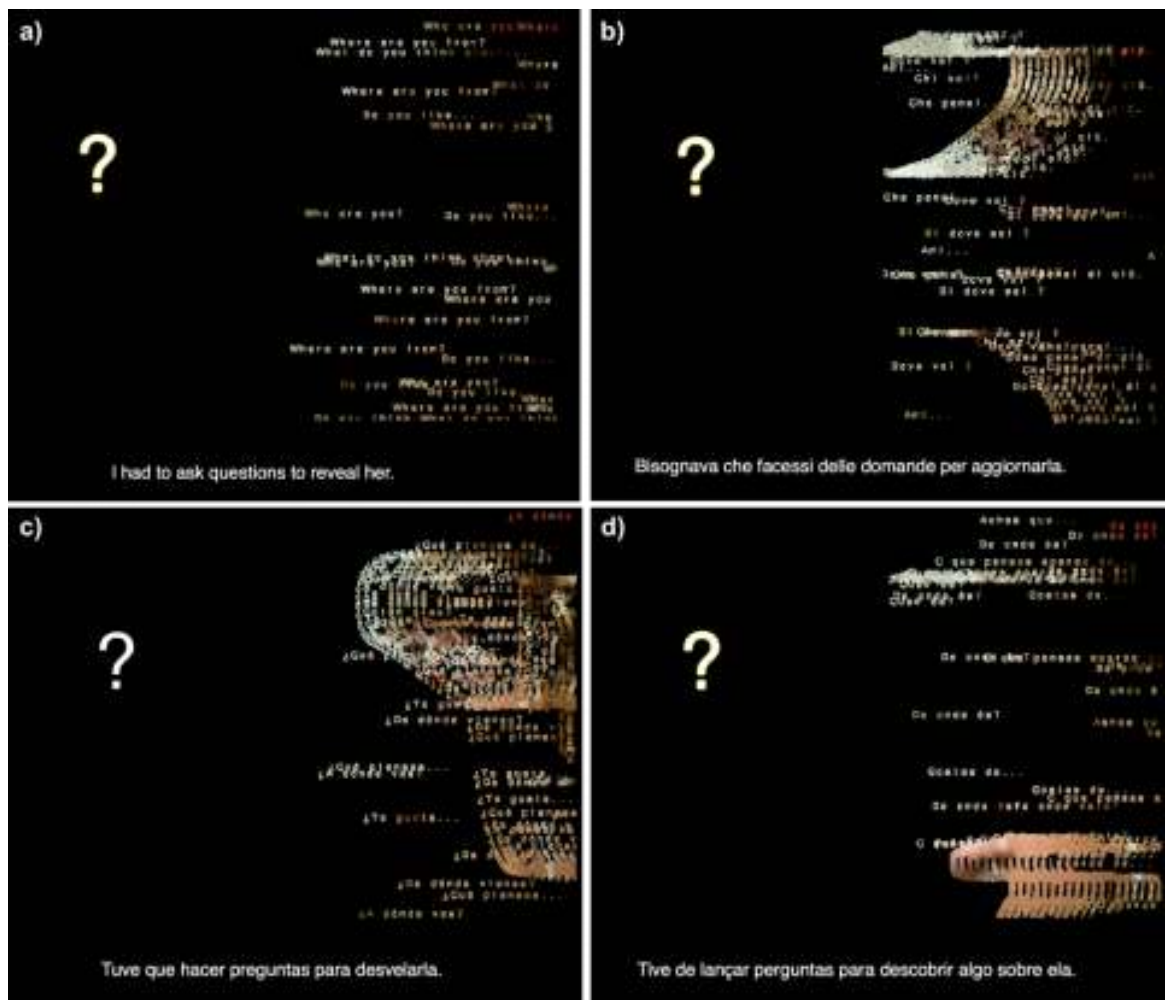

Déprise, Flash version, scene 2 target languages: a) English, b) Italian, c) Spanish, d) Portuguese.

\section{Sound and meaning}

$D P$ is a polyphonic creation. Translating the different voices has played an important role in the translation process. The voices of the narrator, a telephone operator and an adolescent appear in different scenes. These voices act as unidirectional conversations at different rhythms that create an atmosphere of digital heterophony.

In scene 2 (the rendez-vous when the protagonist meets his wife), the author plays with what he calls "alterations" or misunderstandings between the voice being heard and what actually appears on screen. Interestingly, in the French version, these misunderstandings were originally produced with speech recognition software which didn't transcribe the words accurately.
a. Vous habitez la région depuis longtemps? (Vous évitez la légion depuis longtemps
b. Et vous travaillez dans quoi ? (Et vous travaillez l'envoi ?)
c. J'ai l'impression qu'on a beaucoup de point communs (J'ai la pression et la pinte en commun)
d. Je vous trouve vraiment très jolie ! (Chevaux, brousse, bêlement... prés jolis)
e. J'aime votre façon de sourire (Gêne, votre face a des soupirs)
f. Vous voulez marcher un peu ? (Nouveau-nés barges et il pleut)

21 Except for V. Bouchardon, the translators were not aware of the use of a speech recognition software programme to generate these alterations, but they were all aware of a play on phonetics. The stylistic challenge was experienced differently by each of them, di Rosario (Perdersi, 2011) explains:

Another complicated part was what Bouchardon called the "alteration": in fact, in scene 2, I have made some changes in several sentences. I left some of the 
meanings, especially in the main sentences, but I played with the sound of the words in the "alteration," like Bouchardon did in the French version so the meaning of some sentences is totally different.

$$
\begin{aligned}
& \text { was the result of an ongoing discussion with her husband (the author). Moreover, as an } \\
& \text { ESL teacher, V. Bouchardon is used to her students confusing sounds and words in } \\
& \text { English. She relied on her teaching experience to render the "alterations." }
\end{aligned}
$$
English. She relied on her teaching experience to render the "alterations."

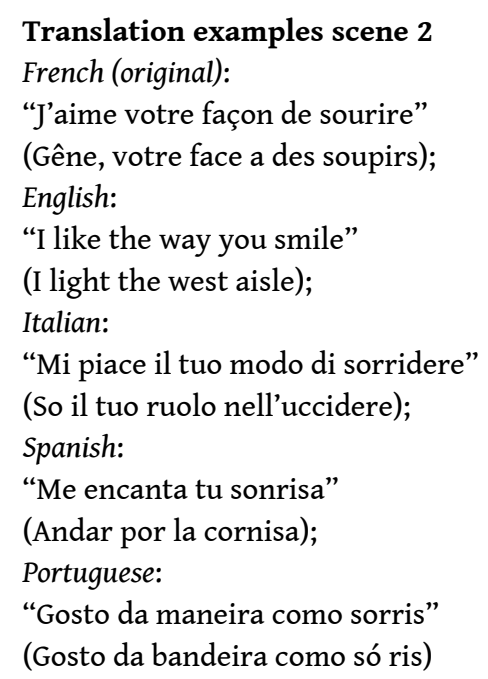
Translation examples scene 2
French (original):
"J'aime votre façon de sourire"
(Gêne, votre face a des soupirs);
English:
"I like the way you smile"
(I light the west aisle);
Italian:
"Mi piace il tuo modo di sorridere"
(So il tuo ruolo nell'uccidere);
Spanish:
"Me encanta tu sonrisa"
(Andar por la cornisa);
Portuguese:
"Gosto da maneira como sorris"
(Gosto da bandeira como só ris)

When I had to translate Déprise, I worked on the alterations in order to obtain the same effects of surprise as in French. For that, I played quite freely on phonetics. I consider this aspect (the recreation of rhythms and sounds) to be the main challenge of any translation. This seems to me to be of major importance in the case of a digital piece, directly appealing to all the senses of the reader. ${ }^{14}$

I found particularly challenging to "transcode" into Portuguese that specific French humour present in all of Serge's interactive fictions. For instance, in the case of cultural transfers, such as thorny idiomatic expressions and the added difficulty in translating homophonic words.

For V. Bouchardon, the experience was a little different. The translation of this part was the result of an ongoing discussion with her husband (the author). Moreover, as an

Translating the dichotomy of meaning and sound is one of the greatest challenges in the translation of scene 2. The translators' imagination and stylistic strategies proved a true process of transcreation, considering that the original version was made with a speech recognition software programme. Certainly, the linguistic and phonetic exercise triggered the following questions: how to translate cultural humour in a work of digital literature? How do different cultures interpret DP? The fact that DP continues to be translated into different languages gives it a "prismatic translation" effect. ${ }^{15}$ On the one hand, the voices on scene 2 belong to different cultural contexts (France, Spain, Italy, Portugal) and individuals; and on the other hand, random cultural elements were used in the translations to fit each individual context. Moreover, these translations show the inextricable connection between multilingualism and multiculturalism as a product and as a challenge of translation. 


\section{Future Trajectories}

\section{The role of indirect translation}

The French (original) and English versions of DP were released simultaneously in 2010. In the interviews, the translators expressed that for some of them the source language alternated between the French and the English version. Therefore, there are two things to consider: 1) the translator's knowledge of other languages, 2) the existing translations at the date of a new version. We know for a fact that the source text used by V. Bouchardon was the French version (2010). In the case of di Rosario (2011) and Alonso (2013), they also worked with the French version (2010) but had the possibility to make aesthetic and linguistic comparisons with the English version (2010); whereas, Marques' (2016) source text was the English version, but he had the linguistic competencies to read the original French version, and make comparisons with the Spanish and Italian versions. The interconnections among the source and target languages open the possibility to speak of a process of indirect translation in digital literature (a translation of a translation ${ }^{16}$ ).

As we can observe, V. Bouchardon's English version (Loss of Grasp, 2010) stands as a referent considering that English acts as a language of reference and encounter between translators (lingua franca). With this in mind, we can ask, up to what extent has $V$. Bouchardon's English translation influenced other versions of DP? Which would be considered as the source text: Déprise (2010) or Loss of Grasp (2010), or maybe both? What is the visibility and literary impact of indirect translations in the future versions of $D P$ ? In a future critical approach, we will certainly investigate the methodological possibilities of indirect translation in digital literature (borrowings, comparisons, dissimilarities), taking as a case study the five new versions of DP (Arabic, Chinese, German, Hungarian and Polish).

\section{The cultural dimension}

DP contains passages strictly related to Western culture. For instance, in scene 3 , the reading from left to right of the love/break up letter in comparison to reading from right to left in the Arabic version; also in scene 3, the inclusion of Georges Bizet's Carmen as background music; in scene 4 , the concept of "hero" expressed by the protagonist's son; also in scene 4 the mention of the word Zoille (a Greek critic); to name but a few examples. The adaptation to the different versions of such aesthetic and poetic effects raise the following questions: how do we substitute or compensate for such cultural aspects in the target culture? How do we deal with cultural transferences when translating works of digital literature? In the example of the love/breakup letter in the Arabic version, we find that the double meaning and visual effect of the linguistic text is relevant to the meaning of the work, but not culturally consistent with the target language. A similar thing happens with Bizet's Carmen where the Opera plays an important role in the construction of the literary atmosphere of the scene - as the protagonist reads the letter, but it might not be suitable for the different contexts of the translations; or the translation of the word (persona) "Zoille" into the different languages. 
In her article, "Digital cultures: A view from French studies and literature," ${ }^{17}$ Erika Fülöp expresses a desire to "counter the stereotype of a homogenous global culture in the Digital Age," insisting on the fact that digital literature preserves the traces of predigital cultures. Fülöp's reasoning is closely related to the translation of digital literature creations today. Should the role of the translator (into English, for example) be to dilute cultural references so that an English-speaking audience may identify with the work, or on the contrary to reproduce any traces of cultural specificity, thus emphasizing the cultural diversity of the productions of digital literature more than their international dimension ${ }^{18}$ If so, is cultural diversity expressed uniquely through the linguistic dimension of digital literature? What about the relation and equilibrium between digital aesthetics and cultural transferences?

\section{The Digital: a reinvented memory}

A link can be made between translation and preservation. Indeed, translations of digital literature can be seen as archives of cultural and technological elements, such as computer software that encodes ways of expression of a specific digital software period (Flash obsolescence and perhaps in the near future, JavaScript), cultural translation of idiomatic expressions and cultural adaptations of the fine arts. The added value of digital technology is not where one expects. The digital medium is not a natural preservation medium but on the contrary it is hell for preservation. But digital technology makes us enter another universe which is a universe of reinvented and not stored memory. ${ }^{19}$

31 From an anthropological point of view, this model of memory is more valuable and more authentic than the model of printed media which is a memory of storage (the book that one stores on a bookshelf just like the memory that one would store in a case of one's brain). Indeed, cognitive sciences teach us that memory does not function on the model of storage and conservation. Preserving is thus permanently reinventing the content - just like translating. The issue is to have an accurate and faithful invention, a reconstruction in which the changes are explicit and commented upon. On a similar level, translation highlights the digital age as a move from a model of stored memory to a model of continuous reinvented memory. Thus, from this point of view, considering the interplay of intersemiotic forms in digital literature (words, images, sounds, gestures) and keeping in mind Reynolds' proposition of "prismatic translation" (2016), works of digital literature can be regarded as a good laboratory to experiment with translation in the digital age.

\section{Conclusions}

This case study was designed to examine the implications of translating a work of digital literature into several languages. We argued that interviewing the translators provided a deeper insight into the different processes and methodologies used, particularly when the goal was to cover more than one target language. We described how the translation process generated a creative tension among media, semiotic forms, programmed writing, aesthetic experience and cultural aspects. This case study has helped us understand that all these elements had to adapt not only to a target culture, language or text but also to a target code. 
The four dimensions of translating digital literature (Portela, Pold and Mencía, 2018) were found in the translation process. On the translinguistic level, the use of indirect translation showed to be a bridge of communication between translators. On the transcoding and transmedial levels, the translators experienced the challenges not only of translating the linguistic text and other semiotic modalities, but also in some cases of adapting them to different programming languages and platforms. Lastly, on a transcreation level, it was proven that the collaboration between the author and the translators was essential to reproduce the literariness and aesthetic elements of the work. Overall, this case study highlights the fact that the exponential growth of digital literature in terms of genre, language and technological apparatus diversity will not only determine the evolution of translation methodologies, but also help to redesign research paths of the field itself.

\section{BIBLIOGRAPHY}

Bouchardon, Serge and Bachimont, Bruno, "Preservation of digital literature: From stored memory to reinvented memory," Cibertextualidades, no. 5, p. 184-202, 2013. [Online] http:// cibertextualidades.ufp.edu.pt/numero-5-2013/electronic-publishing-models-for-experimentalliterature [accessed 23 July 2020].

Bouchardon, Serge, "Figures of gestural manipulation in digital fictions," in Bell, Alice, Ensslin, Astrid and Rustad, Hans (eds.), Analyzing Digital Fiction, London, Routledge, 2014, p. 159-175.

Bouchardon, Serge, "Mind the gap! 10 gaps for digital literature?," Electronic Book Review, 2019.

[Online] http://electronicbookreview.com/essay/mind-the-gap-10-gaps-for-digital-literature/ [accessed 23 July 2020].

Cayley, John, “Translation as process," Amodern, no. 8, Mitchell, Christine and Raley, Rita (eds.), "Translation-Machination", 2018. [Online] http://amodern.net/issues/amodern-8-translationmachination/ [accessed 23 July 2020].

Di Rosario, Giovana and Borràs, Laura, “Translating digital literature: Two experiences and a reflection," Texto Digital, vol. 8, no. 1, 2012, p. 138-162.

[Online] https://doi.org/10.5007/1807-9288.2012v8n1p138 [accessed 23 July 2020].

Fülöp, Erika, "Digital cultures: A view from French studies and literature," Explorations in Media Ecology, vol. 17, no. 3, 2018, p. 271-277.

[Online] https://doi.org/10.1386/eme.17.3.271_1 [accessed 23 July 2020].

Gambier, Yves, "La retraduction, retour et détour," Meta. Journal des traducteurs/Meta. Translators' Journal, vol. 39, no. 3, 1984, p. 413-417.

[Online] https://doi.org/10.7202/002799ar [accessed 23 July 2020].

Marecki, Piotr and Montfort, Nick, "Renderings: Translating literary works in the digital age," Digital Scholarship in the Humanities, vol. 32, no. 1, 2017, p. 84-91. [Online] https://doi.org/10.1093/ llc/fqx010 [accessed 23 July 2020]. 
Marques, Diogo, Reading Digits. Haptic Reading Processes in the Experience of Digital Literary Works, PhD Thesis, Portugal, Universidade de Coimbra, 2018.

[Online] https://estudogeral.sib.uc.pt/handle/10316/81171?mode=simple [accessed 23 July 2020].

Portela, Manuel, Pold, Søren and Mencía, Maria, "Electronic literature translation: Translation as process, experience and mediation," Electronic Book Review, 2018. [Online] http://

electronicbookreview.com/essay/electronic-literature-translation-translation-as-process-

experience-and-mediation/ [accessed 23 July 2020].

Reynolds, Mattew, Translation. A very short introduction, Oxford, Oxford University Press, 2016.

\section{NOTES}

1. Serge Bouchardon and Vincent Volckaert, Déprise, 2010. [Online] http://deprise.fr or http:// lossofgrasp.com.[accessed 12 April 2021].

2. Manuel Portela, Søren Pold and Maria Mencía, "Electronic literature translation: Translation as process, experience and mediation," Electronic Book Review, 2018. [Online] http:// electronicbookreview.com/essay/electronic-literature-translation-translation-as-processexperience-and-mediation/ [accessed 23 July 2020].

3. Serge Bouchardon and Vincent Volckaert, Déprise, 2010. [Online] http://deprise.fr or http:// lossofgrasp.com.[accessed 12 April 2021].

4. Serge Bouchardon and Léonard Dumas, Opacité, 2012. [Online] http://i-trace.fr/opacite/ [accessed $1^{\text {st }}$ April 2021].

5. Serge Bouchardon, Léonard Dumas, Vincent Volckaert, Hervé Zénouda, Giovanna di Rosario (translator) et Valérie Bouchardon (translator), Détrace, 2016. [Online] https://i-trace.fr/untrace/ [accessed $1^{\text {st }}$ April 2021].

6. For further reference: [Online] http://deprise.fr or http://lossofgrasp.com. For a video capture of the interactions, see https://youtu.be/nd6_b158qOs [accessed 12 April 2021].

7. Giovana Di Rosario and Laura Borràs, "Translating digital literature: Two experiences and a reflection," Texto Digital, vol.8, no. 1, 2012, p. 138-162. [Online] https://doi.org/ 10.5007/1807-9288.2012v8n1p138 [accessed 23 July 2020].

8. V. Bouchardon had already translated other works by the author, Les Douze Travaux de l'internaute (2008) and Toucher (2009), di Rosario and Marques will later translate, Opacité (2012) and Détrace (2016).

9. It is important to mention that V. Bouchardon and Marques used their own voices in the English and Portuguese versions. This is an example of transcreation in translation as they performed their linguistic translation by recording their voice and making it part of the digital work. This fact underlines the idea of the translator as a collaborator-mediator, one that is present not only through his/her words (linguistic text) but also through the presence of his/her voice (audio).

10. Piotr Marecki and Nick Montfort, "Renderings: Translating literary works in the digital age," Digital Scholarship in the Humanities, vol. 32, no. 1, 2017, p. 84-91. [Online] https://doi.org/10.1093/ llc/fqx010 [accessed 23 July 2020].

11. Diogo Marques, Reading Digits. Haptic Reading Processes in the Experience of Digital Literary Works, PhD Thesis, Portugal, Universidade de Coimbra, 2018. [Online] https://estudogeral.sib.uc.pt/ handle/10316/81171?mode=simple [accessed 23 July 2020].

12. John Cayley, "Translation as process," Amodern, no. 8, Mitchell, Christine and Raley, Rita (eds.), “Translation-Machination”, 2018. [Online]-http://amodern.net/issues/amodern-8translation-machination/ [accessed 23 July 2020]. 
13. Serge Bouchardon, "Figures of gestural manipulation in digital fictions," in Alice Bell, Astrid Ensslin and Hans Rustad (eds.), Analyzing Digital Fiction, London, Routledge, 2014, p. 159-175.

14. It is important to underline that the Spanish translator (Alonso) communicated with the author in French, “Quand j'avais eu à traduire Déprise, j'avais travaillé les altérations dans le but d'obtenir les mêmes effets de surprise qu'en français. Pour cela, j'avais joué assez librement sur la phonétique. Je considère que cet aspect (la recréation des rythmes et des sonorités) constitue le principal défi de toute traduction. Cela me semble revêtir une importance majeure dans le cas d'une œuvre numérique, faisant directement appel à tous les sens du récepteur."

15. Mattew Reynolds, Translation. A very short introduction, Oxford, Oxford University Press, 2016.

16. Yves Gambier, "La retraduction, retour et détour," Meta. Journal des traducteurs/Meta. Translators' Journal, vol. 39, no. 3, 1984, p. 413-417. [Online] https://doi.org/10.7202/002799ar [accessed 23 July 2020].

17. Erika Fülöp, "Digital cultures: A view from French studies and literature," Explorations in Media Ecology, vol. 17, no. 3, 2018, p. 271-277. [Online] https://doi.org/10.1386/eme.17.3.271_1 [accessed 23 July 2020].

18. Serge Bouchardon, "Mind the gap! 10 gaps for digital literature?," Electronic Book Review, 2019. [Online] http://electronicbookreview.com/essay/mind-the-gap-10-gaps-for-digital-literature/ [accessed 23 July 2020].

19. Serge Bouchardon and Bruno Bachimont, "Preservation of digital literature: From stored memory to reinvented memory," Cibertextualidades, no. 5, 2013, p. 184-202. [Online] http:// cibertextualidades.ufp.edu.pt/numero-5-2013/electronic-publishing-models-for-experimentalliterature [accessed 23 July 2020].

\section{ABSTRACTS}

Déprise is a digital literature piece published online in 2010 (http://deprise.fr or http:// lossofgrasp.com). Progressively, this interactive narrative was translated from French into English (2010), Italian (2011), Spanish (2013) and Portuguese (2016), and more recently into Arabic, Chinese, German, Hungarian, Polish and Russian (2020). Every translation led to an intercultural and transcreative process (Portela, Pold \& Mencia, 2018) between the translators and the author. We asked the English, Italian, Spanish, and Portuguese translators of the work for feedback on the translation process via interviews. In this paper, we use the written exchanges with the translators to question the modes of collaboration between author and translator and the importance of translating specific dimensions of digital literature. Additionally, we briefly discuss some future research trajectories on translating digital literature: the role of indirect translation (Gambier, 1994), the cultural dimension of the works, and translation as reinvented memory.

\section{INDEX}

Keywords: digital literature, translation, multilingualism, transcreation 


\section{AUTHORS}

\section{SERGE BOUCHARDON}

Serge Bouchardon (http://www.utc.fr/ bouchard/) is Professor at the Universite de technologie de Compiègne (France), where he teaches interactive writing. His research focuses on digital creation, in particular digital literature. He is a member of the Board of Directors of the Electronic Literature Organization (ELO). As an author (http://www.sergebouchardon.com/), he is interested in the way the gestures specific to the Digital contribute to the construction of meaning. His creations have been exhibited in many venues in Europe, America, Africa and the Middle East. They have been selected in various online reviews (bleuOrange, Hyperrhiz, SpringGun, The New River).

\section{NOHELIA MEZA}

Nohelia Meza completed her PhD in Translation and Language Sciences at Pompeu Fabra University, Barcelona, in 2017. Currently, she is developping her postdoctoral research project: "Towards a Digital Rhetoric of Latin American Works of Electronic Literature" at the University of Leeds, UK (CONACYT, 2018-2020). Her research interests encompass Latin American Cultural Studies, Digital Rhetoric, Translation Studies and Comparative Literature. She is a member of the Latin American Electronic Literature Network (litElat), the Centre for World Cinemas and Digital Cultures (University of Leeds), and a collaborator of the publishing group (E-literature project) at The Centre for Digital Culture in Mexico City. 